\title{
MECANISMOS DE CONTROLE CONTRAMAJORITÁRIOS E A CONCEPÇÃO COPARTICIPATIVA DE DEMOCRACIA NO ATIVISMO JUDICIAL
}

\author{
CONTROL MECHANISMS AGAINSTMAJORITARIES AND THE \\ COPARTICIPATIVE CONCEPTION OF DEMOCRACY IN JUDICIAL \\ ACTIVISM
}

\author{
LUCAS GONÇALVES DA SILVA ${ }^{1}$ \\ GUSTAVO HERRERA SALGUEIRO ${ }^{2}$
}

\section{RESUMO}

O presente artigo, busca contextualizar os cenários históricos de interpretação jurídica, que, por conta da morosidade de elaboração de leis, dentre outros fatores, para atendimento dos anseios sociais, buscaram soluções alternativas para os anseios sociais. O Poder Judiciário através de uma atuação expansiva, conhecida como Ativismo Judicial, onde, através da utilização de Princípios previstos na Constituição e após a judicialização das demandas pelos jurisdicionados, transforma os anseios desses governados em leis aos casos concretos, principalmente, aqueles em que a inércia ou a omissão dos Poderes Legislativo e do Poder Executivo, obstam a satisfação a esses direitos. Aborda-se os limites dessa atuação expansiva do Poder Judiciário para que não se alcance uma hegemonia desse Poder, frente aos demais poderes. Além de tratar, sobre a visão contramajoritária desse tipo de atuação, por alguns e a concepção coparticipativa de democracia, levando em consideração e respeitando os direitos e garantia do seu semelhante, sejam minorias ou não.

\footnotetext{
${ }^{1}$ Pós-doutor em Direito pela Università Degli Studi G. dAnnunzio (Italia) e pela Universidade Federal da Bahia. Doutor e Mestre em Direito do Estado, na sub-área de Direito Constitucional, pela Pontifícia Universidade Católica de São Paulo-PUC/SP. Professor Associado da Graduação em Direito e do Programa de Mestrado em Direito na Universidade Federal de Sergipe-UFS. Consultor da Câmara de Assessoramento da FAPITEC/SE. Consultor da Coordenação de Aperfeiçoamento de Pessoal de Nível Superior - Capes. Vice-Presidente do Conselho Nacional de Pesquisa e Pós-graduação em Direito - CONPEDI.

${ }^{2}$ Possui graduação em Direito pela Universidade Federal Fluminense (2003). Atualmente é oficial de registros Tribunal de Justiça de Sergipe. Tem experiência na área de Direito, com ênfase em Direito Registral, atuando principalmente no seguinte tema: Registros de títulos e Documentos, Civil e Imóveis.
} 
Palavras Chave: Ativismo Judicial, Atuação Expansiva do Poder Judiciário, Democracia, Concepção Coparticipativa de Democracia

\begin{abstract}
This article seeks to contextualize the historical scenarios of legal interpretation, which, due to the delay in drafting laws, among other factors, to meet social concerns, sought alternative solutions to social concerns. The Judiciary Power through an expansive performance, known as Judicial Activism, where, through the use of Principles foreseen in the Constitution and after the judicialization of the demands by the jurisdiction, it transforms the wishes of those governed in laws to the concrete cases, mainly those in which the inertia or omission of the Legislative and Executive Powers, hamper the satisfaction of these rights. The limits of this expansive performance of the Judiciary are approached so that a hegemony of this Power is not achieved, in comparison to the other powers. In addition to addressing, on the contrary, the majority view of this type of action, by some and the co-participative conception of democracy, taking into account and respecting the rights and guarantees of their fellowmen, whether they are minorities or not.
\end{abstract}

Keywords: Judicial Activism; Expansion of Judiciary; Democracy; Co-Participative Conception of Democracy 


\section{INTRODUÇÃO}

Inicialmente, cumpre destacar que, segundo assinala Antoine Garapon: "uma ordem jurídica pode existir sem um legislador e sem executivo, não pode em contrapartida prescindir de um juiz apto para se pronunciar sobre a interpretação das regras e resolução sobre litígios". (GARAPON,1996)

Ressalta, o mesmo autor, com base no discurso de Portallis, proferido em dezembro de 1801 na discussão preliminar do código civil, que os Juízes existiram antes mesmo das Leis e estes eram pautados pela equidade entre os homens em seus julgamentos, sendo que, tal como deve ser, ainda ,hoje, não podendo, inclusive os juízes , alegar o non liquet nas situações de omissão ou obscuridade legislativa.

Existiram Juízes antes das Leis; estes juízes, nesses tempos de ignorância e de incivilidade, eram ministros de equidade entre os homens, ainda não deixaram de o ser quando não são dirigidos pelas leis escritas; não podem, portanto, com o pretexto da obscuridade e o silêncio das leis, suspender arbitrariamente o seu magistério. (GARAPON ,1996)

A lei, elemento principal do positivismo, deveria supostamente manter a relação entre os julgamentos e a vontade popular. No entanto, percebeu-se que a lei, por si só, não era suficiente para alcançar os objetivos da sociedade na sua elaboração, fazendo com que os juízes não apenas dissessem o direito, mas utilizem-se de elementos externos: jurídicos e metajurídicos, para conjuntamente construírem o sistema jurídico, com isso separa-se a lei do direito.

\footnotetext{
A lei constituía a peça principal do positivismo, já que deveria supostamente manter a relação entre o ofício do juiz e a soberania popular. O Juiz não deveria ser mais do que “a boca da lei”, segundo a celebre expressão de Montesquieu. Contudo, esta lei não essencial à separação dos poderes não é suficiente para guiar o juiz na sua decisão. Este deve recorrer a fontes externas para dizer o direito. A lei já não se confunde com o direito: mantém é certo, uma importância essencial, mas já não pode pretender fundar sozinha todo o sistema jurídico. (GARAPON,1996)
}

Paralelo às leis há a democracia. O Brasil adotou a democracia representativa, onde representantes eleitos pelo povo, recebem o poder-dever de eleger as matérias e as questões 
relevantes e importantes para a sociedade, mas também há algumas hipóteses em que a Constituição permite que essa democracia seja exercida de forma direta, como no caso do plebiscito e referendo.( NUNES JÚNIOR, 2018)

Na obra "O espírito das leis" o Barão de Montesquieu delineou a tripartição das funções do Estado como mecanismo institucional de contenção do poder (separação dos poderes) e garantia da liberdade individual, inspirando a organização de muitos Estados democráticos, com as funções executiva, legislativa e jurisdicional.

Contudo, a atividade jurisdicional quando evidentemente ativa, caracterizada como Ativismo Judicial, gera certa inquietude por conta de um possível desequilíbrio entre os princípios da Separação dos Poderes e a segurança jurídica, tidos como essenciais à manutenção da democracia.

A realidade social não é exatamente espelhada no texto normativo pelo poder responsável pela elaboração da norma. A positivação do direito não é suficiente, adequada, para garantir a aplicação da norma, situação que exige do julgador mais do que uma decisão mecânica e automática, de forma que a falta de perfeita adequação do fato à norma jurídica positivada exige uma solução construtiva.

O juiz passa a ser o novo ator na democracia, ganhando o papel de provedor da justiça. Onde silenciosamente o espaço da democracia migra do Estado para a Justiça, onde o sucesso da justiça é inversamente proporcional ao descrédito que afeta as instituições políticas, devido ao desinteresse e à perda do espírito público.

Segundo ressalta Garapon: “...A justiça torna-se um espaço de exigibilidade da democracia. Oferece potencialmente a todos os cidadãos a capacidade de interpelar os governantes, de os chamar a atenção e de os obrigar a respeitar as promessas contidas na lei...”. (GARAPON ,1996)

Esse deslocamento da Justiça para um primeiro plano, tem um preço, condenando o direito positivo a um déficit permanente, principalmente, pela omissão legislativa do Legislador, que preocupado com as opiniões políticas e na possibilidade de desagradar parte do seu eleitorado, pauta o seu agir, ou melhor o não agir, abstendo-se de legislar sobre determinados temas, sabendo que a solução virá do judiciário.

Contudo, deve-se salientar o perigo dessa nova forma de governança uma vez que o fortalecimento de determinado poder em relação aos demais, pode gerar a tirania, como outrora. 
A justiça não se pode substituir ao político sem correr o risco de abrir caminho para a tirania das minorias, ou até para uma espécie de crise de identidade. Resumindo, um mau uso do direito é tão ameaçador para a democracia quanto a escassez de direito.

(GARAPON, 1996, p. 51)

Além disso, os excessos de direitos criados por juízes podem desnaturar a democracia, uma vez que não fora tomada por quem possua o poder legítimo para a criação das leis, que emana do povo. Além de poder bloquear qualquer decisão a ser tomada pelo Estado, com base em critérios econômicos ou políticos.

Tal paisagem democrática não deixa de conter novos perigos. O Excesso de direito pode desnaturar a democracia; o excesso de defesa pode bloquear qualquer tomada de decisão: o excesso de garantias pode mergulhar a justiça numa espécie de indecisão ilimitada. (GARAPON ,1996, p. 51)

Esses excessos de direitos e de justiça podem gerar uma ameaça à democracia, que merecem ser analisados, pelo menos, para não se cair na substituição do mal pelo mal. Deve-se cuidar para que esse protagonismo judicial, sinônimo do ativismo judicial, não traga esse perigo para a democracia, mas pelo contrário, fomente a justiça e as necessidades dos governados.

Essa desconfiança nos limites e na atuação dos juízes, foi citada por Garapon, fazendo referência ao artigo publicado pela Universidade de Yale em 1989 do, então, Ministro Presidente do Supremo Tribunal Federal de Israel, que salientou que “ o ativismo começa quando, entre várias soluções possíveis, a escolha do juiz é dependente do desejo de acelerar a mudança social ou, pelo contrário, de a travar" (GARAPON, 1996, p.54).

\section{EVOLUÇÃO DO ATIVISMO JUDICIAL: DO POSITIVISMO ATÉ O ESTADO DEMOCRÁTICO DE DIREITO}

O positivismo jurídico Normativista firmou-se como a concepção dominante no direito no decorrer do século XIX e ainda hoje domina o senso teórico dos juristas, tendo como característica a pretensão de constituir em uma avaliação objetiva do direito positivo, para Alexandre Araújo Costa (COSTA, 2010). 
Embora o positivismo tenha se instaurado tanto no Common law quanto na tradição romano-germânica, ele adquiriu características diversas em cada uma dessas tradições.

No Common Law, por exemplo, o direito comum, de matriz jurisprudencial continuou sendo hegemônico, mesmo que o direito legislado ganhasse espaço em uma série de âmbitos do jurídico.

O Código Civil francês de 1804, ao transformar o direito em código, surge como grande expoente e marco zero do positivismo, colaborando para o surgimento de uma ideia positivista. Esse código, conhecido como “A Lei da Boa Razão" incluiu, mediante o fortalecimento da autoridade da lei, a exclusão do direito canônico, a contenção do direito consuetudinário e, principalmente, a limitação ao uso do direito romano, cuja aplicação pelos juízes chegava a funcionar como um limite à própria autoridade real e era, ao mesmo tempo, mais adequada ao contexto econômico e social da época, bem como ao racionalismo dominante no contexto filosófico.

Exigia-se do magistrado evitar ao máximo a influência de seus valores subjetivos e de suas influências ideológicas. Na hermenêutica, buscava-se tornar o discurso jurídico permeável aos outros discursos sociais, onde elementos jurídicos (ou seja, normativos) precisavam ser articulados com elementos metajurídicos (sociológicos, éticos, psicológicos, econômicos etc.) $\mathrm{Na}$ Hermenêutica jurídica moderna deu-se uma tentativa de reduzir o sentido da atividade jurídica a um processo racional e metódico de aplicação de normas positivas a fatos concretos, através da busca de uma decisão valorativa racional. (COSTA, 2010).

Com isso, foi defendido por alguns, que a aplicação do direito deveria caber aos juízes, mas que a interpretação deveria caber ao próprio legislador.

Nos casos de dúvida sobre a norma, a questão deveria ser enviada ao próprio poder legislativo, a quem cumpriria esclarecer o sentido correto, mediante o que se convencionou chamar de interpretação autêntica, por meio de uma lei interpretativa.

O problema que se deu foi que durante algum tempo manteve-se o pensamento de que a técnica de interpretação era um procedimento aplicável somente a textos com sentido gramatical obscuro, mas, com o passar do tempo , começou-se o entendimento de que mesmo a letra fria era objeto de interpretação, estabelecendo-se as diferenças entre as diversas formas de interpretação, como a interpretação gramatical (literalidade da lei) e a interpretação lógica (intenção sobre a literalidade), onde essa literalidade, no caso, tinha um caráter declarativo somente, expressando a intenção principal do legislador sobre a mens legis, enquanto na 
interpretação lógica buscava-se apenas adequar-se aos casos em que o sentido do texto fosse claramente diverso do sentido intencionado.

Com o passar do tempo, com o surgimento dos Códigos, restou evidente que a sistematicidade dos códigos, a extrema fixidez do próprio direito, na medida em que o tamanho e a complexidade dos códigos fazia com que as alterações em seu conteúdo se tornem um processo legislativo muito demorado, dando espaço para o Ativismo Judicial.

Então, como os códigos, em especial, duram por longos períodos, com apenas algumas alterações, isso acaba gerando a permanência de modelos de realidade social que aos poucos vão se defasando frente à realidade jurídica.

Porém, na medida em que essa solução não era suficientemente ágil dentro dos ordenamentos codificados, tornou-se cada vez mais necessário alterar o direito vigente por via interpretativa e não por via legislativa.

Assim, por meio da ideia de função social, muitos juristas passaram a entender que a sua atividade não era a de garantir a adequação da sociedade à norma positiva, mas também a de garantir a adequação dos sentidos normativos às finalidades sociais, o que libertava a atividade jurídica da literalidade da lei quanto, da vinculação a uma pretensa intenção originária do legislador e também da inércia dos conceitos jurídicos tradicionais.( NUNES JÚNIOR,2018)

A partir de Montesquieu e John Locke, passou-se a dividir o poder político em três: o feitor das leis, seu executor e o zelador de sua justa aplicação.

A separação de poderes no contexto do Estado Social tem total pertinência. Os três poderes voltam-se juntos à concretização do projeto social da Constituição. Agora, a omissão de um poder também será controlada pelos demais. Se o legislador não elabora a norma exigida pelo constituinte, é possível ajuizar uma ação judicial pela omissão.

O desafio, principal, para esse sistema de freios e contrapesos, em relação ao Judiciário, diz respeito à existência de uma grande demanda pela busca da efetivação de direitos sociais e uma corriqueira escassez de recursos para fazê-los. Surge a necessidade de formular parâmetros processuais, tais como o uso da tutela coletiva e a reserva do possível e de parâmetros materiais, como a proteção das condições de liberdade e a escolha da solução mais econômica, para que a judicialização da luta por direitos sociais não se torne irracional. 


\section{ATIVISMO JUDICIAL: MECANISMOS DE CONTROLE CONTRAMAJORITÁRIO}

Argumento basilar da ideia democrática consiste na noção daqueles que criam leis e normas devem ser escolhidos pelo povo (NOGUEIRA, 2016). Ou seja, os que teriam legitimidade para tratar do assunto seriam os representantes eleitos na arena majoritária.

Indaga-se em que medida a própria ordem constitucional atribuiu ao Poder Judiciário o protagonismo de controle contramajoritário, no exercício de sua função de proteção dos direitos fundamentais.

Inclusive, pode-se infirmar que a depender da visão de democracia que se adote há a possibilidade de fortalecimento ou não de mecanismos de controle contramajoritário para a garantia de direitos fundamentais, bem como a consequente possibilidade de uma maior judicialização ou não de desacordos de determinada sociedade.

Busca-se uma atuação judicial com autonomia política, mas ao mesmo tempo a política é a criação do direito. O que se busca, de fato, é a falta de influência política nas decisões dos magistrados.

Procura-se uma interação, ótima, entre o agir do judiciário e a política, que é aquela em que a atuação do magistrado garanta que uma decisão política prévia, prevista pelo legislador anteriormente na Constituição ou em lei, seja efetivada.

Todavia há situações do mundo real em que não há norma regente, seja por omissão do poder responsável seja porque essa situação surgiu e não houve tempo suficiente para a realização de uma lei, e, mesmo assim , se exige uma atuação do judiciário, a exemplo do caso; transgêneros; aborto gerado por estupro, etc. Diante da situação concreta, o juiz precisa criar fundamentadamente a norma em concreto que irá reger aquele caso concreto e isso, nada mais é que uma atuação, de certa forma, política por assim dizer, mas não quer dizer que o juiz pode agir discricionariamente, ele deve observar valores legitimados pela sociedade .

Mas, e no caso de não existir norma regente e nem posição da sociedade para orientar o magistrado no caso? Nesses casos, o Magistrado, pautado no Estado Social de Direito, deve guiar-se pela Dignidade da pessoa humana, pela preponderância dos princípios, onde o enfoque em normas transcende aos princípios, que possuem alta carga valorativa. 
$\mathrm{Na}$ atualidade, em Estados cujas constituições possuem a classificação de analíticas, como é o caso da Constituição da República Federativa do Brasil, surge o fenômeno da constitucionalização do direito. Com isso, a constituição invade todos os ramos do direito para regular tudo aquilo que deve ser cumprido.

O Ativismo no processo judicial, por exemplo, aproximando direito da justiça, faz com que o juiz deixe de ser apenas um exegeta e a boca da lei, contribuindo para a concretização dos direitos e garantias sociais previstas, através de uma atuação, por assim dizer, política no caso concreto.

Atuação política essa, inclusive, amparada e resguardada constitucionalmente pela Independência do Poder Judiciário, e também pelas garantias constitucionais do poder judiciário (vitaliciedade, inamovibilidade e irredutibilidade de subsídios), além do ingresso inicial na carreira através de concurso público.

No entanto, para uns, essa abertura do sistema cria uma inquietude que é a Insegurança que essas decisões com o uso do ativismo judicial geram, em especial, por conta da soberania popular e da própria Democracia.

Porém deve-se atentar que os juízes não criam nem inventam o direito, há certos limites a atuação dos Juízes previstos nas próprias leis, a exemplo do instituto da prescrição e do princípio da inércia. Dessa forma, um juiz não pode efetivar um direito por mais que ele seja bom, nos casos de prescrição e, além disso, a jurisdição depende da judicialização da causa, onde o princípio da inércia impede que o juiz exerça a jurisdição caso o processo não tenha sido instaurado por que possua legitimidade e interesse processual. Dessa forma, podemos considerar a seguinte premissa: Para que o ativismo judicial se manifeste é necessário uma judicialização, mas nem sempre que há uma judicialização haverá um ativismo judicial.

Para, Antoine Garapon na obra "Juiz e Democracia: O guardião de promessas", o autor analisa essa inversão de posição da justiça que possuía caráter secundário e adquire o caráter principal em relação ao Estado, através de uma possibilidade de socialização em que a jurisdição é tida como uma forma normal de governo. E como consequência disso a democracia condena o direito positivo a um déficit permanente. A par disso, salienta que, diferente do Totalitarismo, a democracia suscita o conflito. A democracia encontra sua unidade e sua permanência na busca de si mesma, em nome do direito, na procura infinita do seu equilíbrio. $\mathrm{E}$, adverte, que sobre os perigos do excesso de direito que podem desnaturar a democracia, onde 
o excesso de garantias pode mergulhar a justiça numa espécie de indecisão ilimitada. (GARAPON, 1996)

Essa transferência de parcela do poder que estão sendo transferidas e acabam tendo a resolução final pelo poder judiciário, cuidam inclusive de questões econômicas e políticas, que, anteriormente, eram atribuições apenas e exclusivamente do Poder Executivo e do Poder Legislativo. Isso, segundo o Professor Luís Roberto Barroso é uma tendência mundial, tanto em países do Civil Law, quanto países do Commom Law.

No entanto, parte dessa mudança é criada pelo próprio Poder Legislativo!!! Já que muitas vezes o Poder Legislativo não quer ou não consegue criar soluções legislativas por conta de matérias que dividem os seus jurisdicionados, onde os políticos preferem a inercia à ter de se indispor com o seu eleitorado e, paralelamente, sabem que essa omissão, quando da sua judicialização, terá a solução pelo Poder Judiciário, uma vez que o Juiz que não poderá invocar o non liquet para esquivar-se de proclamar a jurisdição e, ainda, pelo fato de que os membros do Poder Judiciário, gozam da prerrogativa constitucional da Vitaliciedade, ficando blindados da insatisfação de parte dos governados .

O professor Luís Roberto Barroso, explica que podem ser identificadas, no Brasil, situações que potencializam o Ativismo Judicial, a exemplo da Constituição da República do Brasil, que é classificada como uma Constituição Analítica e, com isso, acaba gerando uma constitucionalização de todos os ramos de direito, ou seja, ao constitucionalizar o direito permite-se criar pretensões nas pessoas interessadas.

Além disso, segundo descreve o catedrático Professor, a atuação Expansiva do Poder Judiciário Pátrio decorre, também, da possibilidade de interpretação infraconstitucional por juízes de direito. Por fim, aponta ainda que, a previsão em excesso de legitimados para as Ações de Inconstitucionalidade, permite uma judicialização "do sublime ao ridículo", citando como exemplo a medida do Colarinho de Chopp, pelo STJ.

Note-se que, o Ativismo Judicial nada mais é do que o modo de interpretar a Constituição em situações não contempladas explicitamente pelo Constituinte ou pelo Legislador Infraconstitucional. Um bom exemplo deste instituto foi a interpretação dada pela Suprema Corte, a qual gerou a decisão da perda de mandato dos parla

Nesse momento é importante esclarecer que o Ativismo Judicial é uma forma de interpretar a Constituição, a par de situações que não foram tratadas seja pelo Constituinte ou pelo Legislador Infraconstitucional. Como exemplo, podemos citar o caso em que o Supremo 
Tribunal Federal, por ausência de norma, decidiu pela perda do manda dos parlamentares no caso de perda infidelidade partidária , pois, apesar de não haver regra especifica o Supremo Tribunal Federal, por não poder julga o non liquet, interpretou a jurisdição e com base no principio republicano fez a norma para o caso concreto. ${ }^{3}$.

O mundo ideal seria onde o poder Legislativo e o Executivo, exercessem plenamente suas funções típicas e pudessem atender as demandas sociais, previstas na Constituição da República, sem a necessidade de intervenção, através da judicialização, perante o Poder Judiciário.

O Mestre Luís Roberto Barroso, também, salienta que é preciso que se estipule limites por conta da legitimidade democrática. A jurisdição tomada com base, somente no entendimento do judiciário, sem discussões envolvendo os jurisdicionados, detentores do poder oriundo da própria democracia, segundo a própria Constituição Federal, que podem gerar um déficit de legitimidade democrática, principalmente, quando a omissão legislativa deixa de ser uma questão de lacuna e na verdade torna-se uma regra do próprio Legislador, deixando a cargo do judiciário a solução de determinados conflitos e situações da sociedade.

Em relação a esse ponto surge outra inquietude , quanto ao papel contramajoritário do STF, por conta da ausência de legitimidade democrática da investidura dos juízes, em especial na suposta ausência de legitimidade democrática na investidura dos Ministros do STF, onde, através de suas decisões utilizando-se do Ativismo judicial muitas vezes sobrepujam atos e a função típica do Poder Legislativo ou do Poder Executivo, onde esses últimos que na verdade foram verdadeiramente, democraticamente, escolhidos pelo povo.

Mas, para tornar-se ministro do STF, a Constituição da República Federativa do Brasil, ,estabelece algumas regras na própria constituição, onde, os futuros ministros do STF devem ter notável saber técnico, reputação ilibada, sendo indicados pelo chefe do Poder Executivo, indicação essa feita pelo Presidente da República que foi eleito por maioria dos votos do povo e, ao final, devem ser sabatinados, ou seja, aprovados por maioria absoluta no Senado, pelo voto de Senadores que também foram eleitos pelo povo, da mesma forma que o Presidente que indicou.

\footnotetext{
${ }^{3}$ STF, AÇÃO DIRETA DE INCONSTITUCIONALIDADE 5.081 DISTRITO FEDERAL Relator : Min. Luís Roberto Barroso
} 
Percebe-se, salvo melhor juízo, que a escolha dos Ministros do STF é feita pelo povo, indiretamente, através de seus representantes, basicamente como determina as regras democráticas.

Contudo, algumas Cortes Supremas ao exercerem o controle judicial da constitucionalidade da lei, estão assumindo posturas contra majoritárias, que se vão de encontro as maiorias governamentais ou parlamentares. Pautam seu agir, com base na própria autoridade da Constituição, que por sua vez, faz vincular todos os cidadãos e, ao mesmo tempo, garante, a cada um, seus direitos fundamentais de modo incondicional.

Com essa iniciativa, uma Corte Suprema - cujos ministros não são escolhidos pelo povo, porém há com um rito previsto na Constituição - se sobrepõe aos Poderes fundados na representatividade e na regra de maioria. Interpretando continuamente princípios constitucionais, que são indeterminados por natureza, a ideia é que a Corte tome decisões independentes das tendências dos grupos que controlem atos do Executivo e do Legislativo, a fim de que sirvam como parâmetro para a política, o mercado e os cidadãos - mesmo quando quase toda a opinião pública estiver contra eles

O Ativismo Judicial parte da premissa de que a Justiça deve ser isenta, essa ideia têm o objetivo de evitar que seus julgamentos sejam afetados por necessidades conjunturais do Executivo e interesses das maiorias ocasionais do Legislativo ${ }^{4}$.

Decidir diametralmente às ideias da opinião pública, assegurar direitos das minorias e explicitar a justiça de cada decisão são fatores que legitimam as decisões do STF, afirmam aqueles que defendem que a Corte assuma uma postura contramajoritária. Eles também opõem esse papel ao dogma positivista juspositivista da sujeição à lei, sob a justificativa de que ele seria incompatível com as necessidades de sociedades plurais e complexas. Menos rígida e mais flexível na oferta de soluções judiciais, a postura contramajoritária permite que o STF julgue a constitucionalidade de um rol variado de temas relevantes nessas sociedades.

Dessa forma, há os que veem, hoje, que esse papel do Judiciário é, de certa forma, democrático pois o juiz está fazendo isso em nome da democracia, de forma que numa democracia todo poder é exercido em nome do povo e da mesma forma, isso acontece com o Supremo Tribunal.

\footnotetext{
${ }^{4}$ O Estadão: O papel contra majoritário do STF. Disponível em: http://opiniao.estadao.com.br/noticias/geral,opapel-contramajoritario-do-stf,10000065440 Acesso em 24/03/2020
} 
Além disso, somos partidários de que apesar da escolha dos Ministros do STF não ocorrer diretamente pelo povo, ela acontece de forma indireta, onde a própria soberania popular, outrora, fez a sua opção na forma de escolha desses Ministros. Então, de certa forma, não há que se falar em poder contra democrático, uma vez que, por opção do povo, através de seus representantes, a Constituição Federal delineou a forma de escolha dos Ministros do STF.

\section{ATIVISMO JUDICIAL: CONCEPÇÃO COPARTICIPATIVA DE DEMOCRACIA}

Um dos principais motivos que se questiona a legitimidade ou não das decisões provenientes do poder judiciário e que afetem atos provenientes do poder legislativo em sua função típica é que este tipo de comportamento deixaria de observar um dos principais pilares da democracia, que seria a própria noção de que aqueles são os responsáveis e elaboram as leis devem ser eleitos pelo povo e a eles devem prestar contas (NOGUEIRA, 2016).

A divergência entre posições entre Jeremy Waldron e Ronald Dworkin são fundamentais para que se discuta o assunto. Waldron defende que os desacordos morais são intrínsecos à vida em sociedade e que um dos principais direitos, numa democracia, é o de se debater e participar da criação da norma (WALDRON, 2005).

Em outra esteira, Ronald Dworkin aponta que os mecanismos de controle de constitucionalidade seriam essenciais para a vida em democracia, em especial pela necessidade em se proteger minorias e efetivação do papel contramajoritário do poder judiciário (VERBICARO; CASTRO, 2017).

Diante disso, verifica-se que a linhas de pensamento de Waldron e Dworkin divergem acerca do tema, já que Waldron é favorável à atuação do poder legislativo enquanto Dworkin defende uma atuação mais fundamental ao poder judiciário. Suas posições divergem essencialmente por conta do conflito entre visões de democracia, onde para Waldron o importante é a percepção procedimental e majoritária enquanto para Dworkin o que se considera é acepção substancial e contra majoritária (VERBICARO; CASTRO, 2017).

Enquanto Waldron divergindo de Dworkin, entende que a função principal no escopo de uma democracia é o próprio poder legislativo, ou seja, os desacordos e temas controvertidos que devem ser analisados em uma arena majoritária.

A democracia requer que quando haja desacordos em uma sociedade em uma matéria que se necessita tomar uma decisão comum, todo homem e mulher da sociedade tem direito de 
participar em termos de igualdade na resolução destes desacordos. Os processos que isto implica podem ser complexos e indiretos (...) mas todas elas estão orientadas ao mesmo ideal: a participação do povo- de algum modo através de algum mecanismo- basicamente em termos de igualdade (WALDRON, 2005)

Com isso, na linha Ronald Dworkin devemos alertar que um de suas maiores inquietudes seria justamente com a relativização dos direitos de minorias diante do estabelecimento de mecanismos majoritários de decisão. Para ele, a função do judiciário, nestes casos, seria o de corrigir erros e violações que o poder legislativo, ou até mesmo o executivo, na elaboração das normas possa vir a gerar ou causar no exercício de sua função típica.

Nesse sentido, Dworkin defende a concepção constitucional de democracia, nessa concepção é insignificante a falta de cumprimento dos procedimentos, mas a ideia de que, dependendo do caso, tais procedimentos não se mostram satisfatórios para de fato promover a igualdade substancial entre os indivíduos. Por isso, existe o pensamento de que, muito além dos ideais puramente procedimentais, Dworkin defende a prevalência de ideais substantivos (VERBICARO, CASTRO, 2017)

Neste sentido, a visão de democracia para o autor não fica apenas no aspecto majoritário, ou seja, para Dworkin a democracia não se refere única e exclusivamente a governo de maioria (SARMENTO, 2014).

A formulação, portanto, faz referência à necessidade de que a atuação do judiciário efetive a proteção de direitos para todos, sejam maiorias ou minorias. Isso porque Dworkin pressupõe a necessidade de se defender uma concepção comunitária de democracia onde há a obrigatoriedade de proteção e respeito por cada um dos indivíduos que são moralmente independentes (VERBICARO; CASTRO, 2017)

Essa é uma espécie de concepção Coparticipativa de Democracia. Neste tipo de concepção há um comprometimento de que os indivíduos devem agir levando em consideração e respeitando os direitos e garantia do seu semelhante, sejam minorias ou não. A preocupação é pela necessidade de igual respeito e consideração por todos.

A concepção coparticipativa da democracia é diferente: nessa concepção, o autogoverno não é o governo de uma maioria que exerce sua autoridade sobre todos, mas o governo de todas as pessoas atuando como parceiras. Mas pode ser, mesmo assim, uma parceria, desde que os membros aceitem que, na política, devem agir com igual respeito e consideração por todos os outros parceiros (DWORKIN, 2014) 


\section{CONCLUSÃO}

O ativismo judicial, também conhecido como atuação expansiva do Judiciário, vem se desenvolvendo e tornando o Poder Judiciário o principal protagonista das políticas públicas e sociais. Esse protagonismo tem gerado inquietude em determinados setores, pois através desse ativismo pode-se, de certa forma, ultrapassar os limites da jurisdição e ir de encontro à vontade dos jurisdicionados.

Deve-se, portanto, equilibrar a relação do Poder Judiciário com os demais poderes, tendo em vista que no modelo Democracia que vivemos é necessário que os poderes sejam equilibrados entre si, havendo uma hegemonia entre eles e que não haja sobrelevância de um sobre os outros, já que, a Democracia requer um equilíbrio entre esses poderes. Não obstante, deve haver limites para regular essa hegemonia e isso, depende também da atuação dos outros poderes, pois o Poder Judiciário não deve agir com extremadamente na sua função judicial.

Para isso, devemos separar duas situações:

A primeira, em que o Poder Legislativo, efetivamente tenha atuado. Nesse caso, o judiciário deve seguir a escolha feita pelo legislativo que, definitivamente, tem esse papel e tem a representatividade através do voto, salvo situações flagrantemente contrarias à Constituição. Como exemplo de jurisdição com base na decisão política tomada pelo Legislador e pelo Poder Executivo, temos a judicialização da chamada Lei da Copa, onde no Supremo Tribunal Federal, através da ADI 4976, pelo voto do Ministro Luís Roberto Barroso, restou claro que a decisão foi tomada em respeito à decisão política tomada pelo Congresso Nacional e pelo Poder Executivo, conforme transcrição abaixo.

\footnotetext{
O ministro Luís Roberto Barroso acompanhou integralmente o voto do relator. "Tratase de uma lei que foi aprovada pelo Congresso Nacional e sancionada pelo chefe do Poder Executivo", afirmou. "Não acho, por mais crítica que seja a visão que um juiz possa ter desta decisão política, que o Supremo possa, deva ou queira ser juiz de decisões de conveniência e oportunidade tomadas pelos agentes públicos eleitos" ${ }^{\text {. }}$.
}

A segunda situação, seria quando o legislativo não tenha atuado. Nestes casos, a inércia ou omissão por parte do Poder Legislativo ou do Poder Executivo, gera um dever poder do

\footnotetext{
${ }^{5}$ ADI 4976. Disponível em: < http://www.stf.jus.br/portal/cms/verNoticiaDetalhe.asp?idConteudo=266270>
} 
Judiciário em atuar. A exemplo, quando o Supremo decidiu que a união homoafetiva estável tem o mesmo regime jurídico de entidade familiar.

Por fim, devemos entender a Democracia não só como a vontade das maiorias, mas também a defesa das minorias e, tratando-se do Ativismo Judicial, quando ele é exercido pelos juízes com equidade, torna-se justificado e necessário o papel Democrático do Ativismo Judicial.

\section{REFERÊNCIAS BIBLIOGRÁFICAS}

SARMENTO, Vitor. O papel da jurisdição constitucional à luz das teorias de Ronald Dworkin, Jurgen Habermas e Jeremy Waldron. In: Derecho y Cambio Social, ano 11, n.35, 2014. Disponível em: <https://dialnet.unirioja.es/servlet/articulo?codigo=5472779>. Acesso em 23/03/19

GARAPON, Antoine. O juiz e a Democracia: O Guardião das Promessas, Editions Cole Jacob, 1996. Tradução: Francisco Aragão

NUNES JÚNIOR, Flavio Martins Alves. Curso de direito constitucional. $2^{\circ}$ ed. São Paulo: Ed. Thomson Reuthers, 2018, p. 1.202.

Costa, Alexandre Araújo. Universidade de Brasília - UnB.Faculdade de Direito - Curso de Doutorado .Direito e Método: diálogos entre a hermenêutica filosófica e a hermenêutica jurídica. Orientador: Miroslav Milovic. 2010

NOGUEIRA, Carolina. O controle de constitucionalidade no Brasil e as teses defendidas por Jeremy Waldron e Ronald Dworkin. In: Revista Faculdade de Direito Sul de Minas, Pouso Alegre, v. 32, n.2, jul-dez. 2016, p. 163-176. Disponível em: $<$ https://www.fdsm.edu.br/mestrado/revista_artigo.php?artigo=215\&volume=>. Acesso em 23/03/2018.

TOZZI, Piero A.; MARCILESE, Sebastián; GONZÁLES, Rossana Muga. EL ACTIVISMO JUDICIAL EN LATINO AMÉRICA. ANÁLISIS A RAÍz DE LA RECIENTE JURISPRUDENCIA ARGENTINA PROABORTO. Revista Juridica, [S.1.], v. 3, n. 40, p. 1- 37, jan. 2016. ISSN 2316-753X. Disponível em: <http://revista.unicuritiba.edu.br/index.php/RevJur/article/view/1358/915>. Acesso em: 18 abr. 2020. doi:http://dx.doi.org/10.21902/revistajur.2316-753X.v3i40.1358.

VERBICARO, Loiane da Ponte Souza Prado. Judicialização da política, ativismo e discricionariedade judicial. Rio de Janeiro: Lumen Juris, 2017.

VERBICARO; Loiane; CASTRO, Pietra. Direito, Controle Judicial e Democracia: O debate entre as teorias democráticas de Jeremy Waldron e Ronald Dworkin. In: Revista Direito em Debate- UNIJUÍ, n.47, jan-jun, 2017, p. 177-204. Disponível em: <https://www.revistas.unijui.edu.br/index.php/revistadireitoemdebate/article/view/6829>.Ace sso em 23/03/2018. 
WALDRON, Jeremy. Derecho y desacuerdos. Madrid e Barcelona: Marcial Pons, Edicionesjurídicas y sociales, S.A, 2005. 